Linguistik Terapan 17 (2) (2020): 111-122

Jurnal Linguistik Terapan Pascasarjana

Available online

http://jurnal.unimed.ac.id/2020/index.php/JLT-Unimed

\title{
COGNITIVE CONSIDERATION IN PERSUADING READERS IN ARGUMENTATIVE WRITING
}

\author{
Betharia Br. Sembiring Pandia \\ Berlin Sibarani \\ Sumarsih \\ English Applied Linguistics Program \\ Postgraduate Program-Universitas Negeri Medan
}

Diterima Mei 2020; Disetujui Juni 2020; Dipublikasikan Agustus 2020

\begin{abstract}
The objectives of this study was to describe the writers' ways of persuading readers in argumentative writing. This study followed the theory of Ramage et.al. (2016) about the ways of persuading readers which comprises of text structure, reasoning, and persuasive appeal. This study used descriptive qualitative design. The data of this study were gathered by using elicitation technique, asking the $8^{\text {th }}$ semester of undergraduate students to write argumentative text under predetermined topic Social Media Should be Banned with three intended readers, they were: Junior High School, Senior High School, and Undergraduate students.This study revealed that the subjects manipulated the text structure by presenting three-layered text structure of argumentative writing, and presenting the pseudo-evidence and organizing cause and effect relationship in terms of the reasoning aspect.
\end{abstract}

Keywords: Cognitive Consideration, Argumentative, Writing, Persuasive

How to Cite: Br. Sembiring Pandia, Betharia. (2020). Cognitive Consideration in Persuading Readers in Argumentative Writing. Jurnal Linguistik Terapan-Pascasarjana Unimed. 17 (2) :111-122.

ISSN: $2407-7410$

\section{INTRODUCTION}

Cognitive consideration refers to the process of giving careful thought of something. In the process of writing, a writer gets through cognitive consideration on how to express his 
ideas so it can be well accepted by the readers. Persuading readers is comprised of the ways of getting the readers accept, agree with the writer's point of view or even do something based on the writer's expectation. This is called as persuasiveness. Connor (1991:67) states that persuasiveness can be measured through three important factors in argumentative writing, they are: (1) the text structure. Text structure adds persuasiveness since ideas should be segmented in paragraphs in order to not confound the readers about main points of the writers. It belongs to the persuasiveness dimensions because readers will likely hold their motivation to continue reading if the text consists of well-organized ideas; (2) reasoning $(\log o s)$. Reasoning or logos focuses on the internal consistency and clarity of the argument. Reasoning for persuasiveness of argumentative writing refers to the use of explicit elements of argument such as claim, ground, and warrant; and (3) persuasive appeals (ethos and pathos). Ethos focuses on the credibility of the writer which is projected in the presence of alternative views in his writing. In addition to this, the writer also needs to balance their point of view with the potential counter-argument. By doing so, the writer can enhance their credibility as being a knowledgeable person of the issue. Pathos focuses on the writer's way to get the readers' emotional attractiveness. It is characterized by the use of concrete language, specific examples and illustration, images, and metaphors.

The ways of persuading readers in argumentative writing which are realized in English as native Language (ENL) and English as Second Language (ESL) above may be projected differently in Indonesia in which English is used as a foreign language (EFL).

Therefore, this study was focused on ways of persuading readers that were made by EFL students in their argumentative writing.

\section{METHODOLOGY}

This study is conducted by using descriptive qualitative research design. This research is intended to describe the undergraduate students' ways of persuading different intended readers. The data of this research is the sentences of the students' writing that represent their ways of persuading readers.

\section{FINDINGS AND DISCUSSIONS}

In persuading readers, the subjects used two major elements of persuasiveness of argumentative writing, they were: (a) text structure, and (b) reasoning.

In text structure, the subjects presented (a) Introduction; (b) writer's position; and (c) conclusion. Unlike the theory of Ramageet.al (2016:61), the subjects' way of persuading 
readers were in absence of opposing view paragraph. To persuade the intended readers, the subjects manipulated every part of the text structure. In terms of reasoning, as the way to make the arguments logical to the readers, the subjects provided ground (evidence/data) and claim in their own way, which was different from what had been stated in the theory of Toulmin (1984:20). Meanwhile, persuasive appeals which were also the elements of persuading readers were not found in the data. The ways of persuading readers is seen in the following details.

\section{Text Structure}

Organizing ideas is one of the ways in persuading readers; and it is realized in the form of text structure. The text structure of argumentative writing, according to Ramage et.al (2016:86) consists of introduction, writer's position, opposing view, and conclusion. Each parts of this structure can be manipulated in order to achieve the goal of argumentative writing that is to persuade readers.

By Applying Definition, Personal Opinion, Issue, and Implicit Thesis Statement in Introductory Paragraph

\section{Definition}

In developing the Introduction of the argumentative writing, the subjects count on definition as shown in data 1.

Data 1

Social media refers to the means of interactions among people in which they create, share, and/or exchange information and ideas in virtual communities and networks.

In data 1 , the introduction is begun with Social media refers to the means of interactions among peoplein which they create, share, an exchange information and ideas in virtual communities...; and it belongs to definition. Definition refers to detailed description of something in attempt to avoid readers' misunderstanding and to gain more precise image of what is being defined (Ary et.al $2010: 36$ ).

The term refers used in the data is intended to describe social media as the means of communication. To gain more precise image of what social media is, the subject also presented the function of social media as seen in the clause in which they create, share, and exchange information and ideas. Therefore, it was true to say that the sentence was called definition. The subjects developed the introduction by giving the definition. For this reason, the subject believed that giving definition could catch readers' attention. 
It was different from what the experts (Ramageet.al, 2016) stated about the introduction in argumentative writing. The introduction should be begun with the presentation of current event, memorable scene, illustrative story related to the topic being discussed in order to catch readers' attention.

The use of definition in the introduction to begin the argument by the subject might be meant to catch readers' attention in different way from that of stated in the theory. It might be true to say that the subjects assumed readers would not be interested in the topic being discussed if the readers did not know what the topic was. Therefore, giving a definition to readers became one way for the subjects to catch their readers' attention.

\section{Personal Opinion}

In addition to the presentation of definition, the subjects also provide their personal opinion to catch readers' attention in the introduction, as seen in data 2.

Data 2

Nowadays, most teens has been influenced by social media. They usually used social media to post and upload status, picture.

In data 2, the sentence Nowadays, most teens has been influenced by social media is classified as personal opinion because it contains the subject's beliefs in the social media. This is in line with the definition of personal opinion put forwarded by Sims (2016) in which he states that personal opinion is what someone believes about an idea, question, or topic while Ramage et.al (2016) claim that introduction should be developed by providing facts of current event, memorable scene, and illustrative story. By comparing the sentence (Nowadays, most teens has been influenced by social media) to Sims (2016) and to Ramage et.al (2016), it is logical to conclude that the sentence is personal opinion.

In relation to the personal opinion provided above, the subject might think that the readers would accept the writer's statement even if it was only personal opinion. This might be caused by certain feature of mode of communication. Qingxue (2003) mentioned that Western people expected messages to be detailed, clear-cut, and definite. It meant that if there are not enough data or not apparent, they will ask blunt questions because they feel uncomfortable with vagueness and ambiguity which is often associated with limited data. In contrast, Eastern people are comfortable with ambiguity and nurture interpersonal harmony. This theory may be the reason for the absence of empirical data in subjects' writing. The subjects and the readers of this writing are Asians, so the subject may think that personal opinion is enough to get the readers accept his argument. 
After presenting personal opinion, the subjects present the issue as it can be seen in data 3 below:

Data 3

Social media itself has many positive effects to get and share information and also we can get many friends. But, besides of the positive effect, social media also has many negative effects especially for Junior High School students. They are to make them lazy or disturb their focus and to waste their money. That's why social media should be banned for Junior High School students.

Data 3 was called issue. Issue refers to debatable topic requiring different opinion which indicates one's position towards the topic that needs to be discussed (Knapp $\&$ Watskins, 2005:201). The word debatable means that it emerges positive and negative side of something.

The issue in data 1c was started from L.4-L.6 Social media itself has many positive effects to get and share information and also we can get many friends. The phrase positive effects referred to the benefit of using social media. The issue completely existed in data 1c as in L.7-L.11 Besides the positive effect, social media also has negative effects... By saying that social media also has the negative effect, it means that the data in 1c was said as an issue.

In these lines, the subjects stated the positive sides of using social media such as getting and sharing information; and getting many friends. Following this idea, in L.7-L.10, the subject mentions the negative sides of social media such as making them lazy or disturbing their focus, and wasting their money.

\section{Implicit Thesis Statement}

Besides introducing the issue, the subjects present their thesis statement by using thesis statement as seen in data 4.

Data 4

They depend on social media to get more followers and to become outstanding. This habit that is using social media obviously lead the teens to some bad effects.

In data 4 , thesis statement is stated implicitly. Thesis statement is defined as the sentence that represents writer's position on an issue (Ramage et.al, 2018:314). By taking the definition of thesis statement, data 4, in L.6-L.7, was categorized as thesis statement. It was proven by the subject's judgment as well as her position on social media in which she stated social media could cause bad effects on teenagers. Besides, the thesis statement was 
implicitly stated as the writer's position implied in the phrase of bad effects on social media which indicates the writer's agreement on banning social media.

The implicit thesis statement might be affected by the subjects' culture as being Asians. Chen \& Starosta (2003) asserted that Asian people had reserved communication style. It leads Asians to express themselves in a subtle or indirect way in verbal or non-verbal expression communication especially for the purpose of understanding and avoiding confrontation. It can be seen when Asians feel a need to reject their counterparts' request or action which potentially brings damage to harmony. Based on this theory, it is assumed that the implicit thesis statement made by the subjects was also due to their wanting to be polite by implicitly showing their position about an issue. They may think about readers' prospective disagreement with their point of view, and they also want to maintain harmony with the readers.

\section{By Applying Writer-Based Reasons in Writer's Position Paragraph}

After presenting the introduction, the subjects presented their writer's position paragraph which was different from that of mentioned in the theory (Ramageet.al, 2016). In developing the paragraph of Writer's position, the subjects used writer-based reasons in order to make their arguments persuasive to the intended readers as shown in data 5.

Data 5

Secondly, the social media can make someone become lazy. They will not be able to manage their time because they have been enjoy to play their social media. Their time will pass useless.

In data 5, writer's position was presented by using writer-based reasons. Writer-based reasons is defined as expressing arguments which is simply based on the writer's perspective and written for himself (Flower \& Hayes, 1979). It reflects the associative, narrative path of the writer's line of thoughts. With reference to this definition, writer-based reason can be seen through subject's statements as seen in L.17-L.19. Within these lines, the subject mentioned the effect of social media on someone's activity. The subject mentioned that users would enjoy using social media much so that they could not manage their time well. The underlying assumption here was that it was wrong to use social media. But, this assumption might not resonate with readers, as students, who thought that social media was needed to support their studying. Thus, it was seen that the subjects merely expressed her argument without considering the points that effectively anchored within the audience beliefs and values. 
By Repeating Previous Sentences and Writing Irrelevant Suggestion in Concluding Paragraph

\section{By repeating previous sentence}

To end the argumentative writing, the subject wrote Conclusion paragraph which was different from that of stated by experts (Ramageet.al, 2016). The subjects tended to repeat previous sentences from the Introduction and Writer's position paragraph. The repetition is described in data 6.

Data 6

In conclusion, social media should be banned for students at Junior High School because it gives more negative effects for them.

In data 6, the subject provided a paragraph which belonged to conclusion. A conclusion is defined as the end result of an argument. It is the main points that a writer makes in her paper (Sims, 2012:17). Data 6 shows that it is a conclusion as it is begun with the conjunction In conclusion...; and placed in the last paragraphs which indicates the final decision of the subject on her arguments (L.41-L.42). However, the conclusion as in data 6 did not consist of her main points. In L.41, the subject stated her position towards the topic which was the repetition of thesis statement previously mentioned in introductory paragraph. This was to say that the subject did not reword her points on writer's position paragraph to the concluding paragraph. However, it was mentioned in the theory of Ramageet.al (2016) that concluding paragraph should consist of the summary of the writer's points of argument. As the data differed from the theory, it might be due to the subjects' lack of knowledge about writing a concluding paragraph. The subjects might think that restating their thesis statement was enough to give a sense of closure and emphasis of ideas to the readers.

By Writing Irrelevant Suggestion to the Topic

In addition to the conclusion that sums up overall ideas of subjects' argument, concluding paragraph also consists of suggestion. Suggestion is supposed to evoke readers to take actions (Ramageet.al, 2016).

The way the subjects presented the suggestion is shown in data 7 below.

Data 7

I suggest for teenagers nowadays you must be use your social media sufficiently.

Data 7 is called suggestion. Suggestion is defined as a proposal offered which is used to shape one's decision (Spears, 2013:451). In data 5, conclusion was explicitly shown through the word suggest. Based on the data above, it could be seen that it was a statement of 
offering readers to use social media sufficiently. So, data 7belonged to suggestion. It was placed within the concluding paragraph, specifically in the last layer of text structure.

However, based on data 7 above, it is shown that the suggestion is irrelevant to the topic which required the subjects to decide to ban or not to ban social media. In other words, it was said as being irrelevant because the subject did not stand on any position toward the topic. The subject seemed to let the readers choose whether they could use social media or not. Meanwhile, a suggestion should have about the actions offered to the readers, but it was not found in subjects' statement of suggestion.

The irrelevant suggestion in the subjects' writing might be due to the subjects' difficulty on focusing the topic and on linking it to the suggestion logically.

\section{Reasoning}

The subjects persuaded their readers by utilizing their reasoning in writing argumentative text. The subjects' reasoning was laid on using simple sequence of cause and effects; and using pseudo-evidence which is shown below in detail.

\section{By Using Pseudo-Evidence}

Pseudo-evidence is the example which is not factual; it does not have any data and tend to be more like the writer's opinion. This concept was not found in theory, but it was created to accommodate the facts in the data. With reference to this, it was found that the subjects use pseudo-evidence in writing their argumentative text as seen in data 8 .

Data 8

Firstly, social media make people do the crime easily. For example: "Audrey case” We can see that the case happened because of bullying in social media. Audrey was almost die because of bullying and mistreating by some people. It is surely make Audrey get mental pressure. To avoid the crime in social media, it is better to avoid the social media.

In data 8 , subjects' reasoning was accompanied by pseudo evidence. Evidence refers to the all the verifiable data and information that a writer might use as support for an argument (Ramageet.al, 2016:88). Verifiable in this definition means that the data and information should be objective in which the source and the content of the information itself refer to factual evidence.

By using the definition of evidence as the criteria to determine whether something is called as evidence or not, in data 8, specifically in For example: Audrey case. We can see that the case happened because of bullying in social media. Audrey was almost die because of bullying and mistreating by some people. The subject tried to provide evidence in order to 
clarify what she means by do the crime easily (L.17). It was realized by providing "Audrey", as a bullying case. However, the example in which the writer tried to provide as evidence was not accompanied by verified information since the subject did not show any source and details of the information to support her own statement in L.16-L.17. Though it did not belong to factual evidence, the example in data 8 could be called as pseudo-evidence since it was intended to support the subject's argument stating that social media facilitates people to do criminality.

\section{By Organizing Cause and Effect}

The data analysis showed that the causes and effects are: (a) succeeding; and (b) sequentially or sequentially presented in the data as it was stated by Martin and Rose (2008). Each logical relations of this type of sequence is presented as follow:

\section{Succeeding}

Data 9

Firstly, the social media can make someone do the crime easily. For instance, someone can bully someone else by their social media, like Facebook, Instagram, etc. Someone also can spread the hoax to others in order to make someone else can not live comfortable. Then, someone can do the plagiarism.

Secondly, the social media can make someone become lazy. They will not be able to manage their time because they have been enjoy to play their social media. Their time will pass useless.

Data 9 is categorized as succeeding cause and effect explanation. It is indicated through the effect that immediately comes after the cause. It can be seen in L.10 and L.17 which represent the subject's agreement on banning social media. In L.10, it was mentioned that social media made someone to do criminality easily. By using the word make, it meant that social media was the cause, while the effect was about the easiness of doing criminality. The succeeding cause and effect explanation is also seen in L.17. In this line, it was mentioned that social media could make someone lazy. Similar to the word used in L.10, the word make indicates that social media is the cause, and the effect is lazy.

From the two points above, it is shown that both of the points are not sequentially related; they are separated ideas that have their own cause-effect relationship.

\section{Sequentially}

Data 10

First, most teens stay connected to the internet, accessing social media the whole time. They always check their social media account on the smartphone from the time they wake up 
in the morning till they back to sleep at night. They usually stayed up at the whole night. This habit could ruin their sleep pattern and it would lead to a higher risk of exhaustion and depression. It can affect their performance at school.

Data 10 is categorized as sequential explanation of cause and effect. Martin and Rose (2008:150) states that sequential explanation is constructed by a series of events that is chained one to another. By using this definition to categorize the logical relations between events, it is relevant to say that it belongs to sequential explanation of cause and effect. Data 10 presents that it is social media that causes one bad effect that is disturbing one's sleep pattern as seen in L.12. The word sleep pattern as the impact of using social media becomes the cause of exhaustion as stated in L.13. Then, the exhaustion affects the students' performance at school seen in L.14. The flow from sleep pattern, exhaustion, and also students' performance at school shows how one problem that is social media can emerge one bad effect and causes one to another.

Despite of the category as sequential cause and effect, the subjects did not provide detail explanation of how sleep pattern could cause exhaustion and affect students' performance at school. The subjects let the readers to link cause-effect relationship to their own understanding. This might be the reason of assuming writers' not caring about their intended readers.

The research findings showed that the subjects used similar elements of text structure and reasoning to persuade all intended readers. The elements of each layer of text structure including the introduction, writer's position paragraph, and conclusion were manipulated in order to persuade all groups of intended readers. It meant that the subjects did not have specific ways of persuasion for each group of readers; they merely expressed their ideas in which they assuredit as being persuasive to all groups of intended readers. The similar manipulations were also done in terms of reasoning as the way for making the ideas be logically accepted by the readers. In reasoning, the subjects used pseudo-evidence and organizing cause-effect relationship in their argumentation. All of the elements that the subjects used in their argumentative writing were not fully the same as what has been stated by the theory of Connor (1991) about persuasiveness of argumentative writing, the theory of Ramageet.al (2016) which is about the text structure of argumentative writing, and the theory of Toulminet.al (1984) about the elements of reasoning. In addition, there were some new labels made by the researcher to be represented as a new finding. For example, in introductory paragraph, the researcher used definition, personal opinion, and introduced the 
issue to catch readers' attention; in contrast, Ramageet.al (2016:61), relating argument to the current event, memorable scene, and illustrative story tocatch readers' attention. In the second research question, the finding shows that readers' domain knowledge and text organization were considered by the subjects in persuading readers in their argumentative writing.

Based on the explanation above, both of the ways of persuading readers and also the cognitive considerations in writing argumentative text were similar to all of the intended readers. It meant that the subjects did not have specific consideration for specific intended readers. For this reason, it could be said that this study focused on subjects' awareness of the readers (reader-awareness) rather than linguistics knowledge in writing.

A study conducted by Wang (2016) was in line with the current research finding. She found that students interacting with audience during revision produced significantly more argumentative elements for reader awareness than those who were assigned to write for imagined readers and interacting audience during planning. Wang's finding support the current research finding in which the subjects or writers would be difficult to present the elements of argumentative writing when they were not directly faced to the intended readers. As the result, the subjects tended to use the same cognitive considerations and similar ways in persuading the various intended readers.

In spite of having this research on EFL context, this study had some limitations in terms of giving invariant topics of writing which would be beneficial to get subjects' perspectives toward the topic whether or not their culture contributes various ways and considerations about persuading readers, as it was mentioned in the second point of cognitive consideration in argumentative writing which was mentioned in Deane et.al (2008:17).

\section{CONCLUSIONS}

The subjects' ways of persuading readers are different from what the experts' statement in the theory. It was especially related to the text structure and reasoning as the ways of persuading readers. In the text structure, the subjects use three-layered text structure instead of the text structure of argumentative writing which is proposed by Ramageet.al (2016). The three-layered text structure consists of: (a) introductory paragraph; (b) writer's position paragraph; and (c) conclusion. In the introductory paragraph, the subjects initiate the argument with (1) definition; (2) personal opinion; and (3) issue. In writer's position paragraph, the subjects use writer-based reasons; while to end up the argumentative writing, 
the subjects present the conclusion which is repetition of the previous sentences instead of the summary of arguments and irrelevant suggestions to the topic.

\section{REFERENCES}

Ary, D., Jacobs, L.C. and Sorensen, C. 2010. Introduction to Research in Education. Belmont: Wadsworth Cengage Learning.

Deane, P., N. Odendahl, T. Quinlan, M. Fowles, C. Welsh, \& J.B. Tatum. 2008. Cognitive Models of Writing: Writing Proficiency as a Complex Integrated Skill. Princeton: Educational Testing Service.

Flower, L., and J.R. Hayes. 1979. A Cognitive Process Theory of Writing. College Composition and Communication.

Knapp, P., and M. Watkins. 2005. Genre, Text, Grammar. Sydney: University of New South Wales Press.

Ramage, J., J.C.Bean, \&J. Johnson. (2016). Writing Arguments: A Rhetoric with Readings. New York: Pearson Education, Inc.

Spears, D. 2013. Improving Reading Skills. New York: McGraw Hills.

Toulmin, S., and R. Richard. 1984. An Introduction to Reasoning. New York: Macmillan Publishing Company.

Wang, S. 2016. An Experiment on Audience Awareness Effects on College Students' Argumentative Writing. Nebraska: College of Education and Human Sciences University of Nebraska, United States. 